Published as: Nat Neurosci. 2008 July ; 11(7): 816-822.

\title{
Seizure Termination by Acidosis Depends on ASIC1a
}

\author{
Adam E. Ziemann ${ }^{1,2, f}$, Mikael K. Schnizler ${ }^{3, f}$, Gregory W. Albert ${ }^{4}$, Meryl A. Severson ${ }^{4}$, \\ Matthew A. Howard III ${ }^{4,5}$, Michael J. Welsh 1,2,3,5,7, and John A. Wemmie $5,6,8$ \\ 1 Medical Scientist Training Program, Roy J. and Lucille A. Carver College of Medicine, University of Iowa, \\ Iowa City, Iowa 52242
}

2 Department of Molecular Physiology and Biophysics, Roy J. and Lucille A. Carver College of Medicine, University of Iowa, Iowa City, Iowa 52242

3 Department of Internal Medicine, Roy J. and Lucille A. Carver College of Medicine, University of Iowa, Iowa City, Iowa 52242

4 Department of Neurosurgery, Roy J. and Lucille A. Carver College of Medicine, University of Iowa, Iowa City, Iowa 52242

5 Neuroscience Program, Roy J. and Lucille A. Carver College of Medicine, University of Iowa, Iowa City, Iowa 52242

6 Department of Psychiatry, Roy J. and Lucille A. Carver College of Medicine, University of Iowa, Iowa City, Iowa 52242

7 Howard Hughes Medical Institute, Roy J. and Lucille A. Carver College of Medicine, University of Iowa, Iowa City, Iowa 52242

8Department of Veterans Affairs Medical Center, Iowa City, IA, 52242

\section{SUMMARY}

Most seizures stop spontaneously. However, the molecular mechanisms remain unknown. Earlier observations that seizures reduce brain $\mathrm{pH}$ and that acidosis inhibits seizures indicated that acidosis halts epileptic activity. Because acid-sensing ion channel-1a (ASIC1a) shows exquisite sensitivity to extracellular $\mathrm{pH}$ and regulates neuron excitability, we hypothesized that acidosis might activate ASIC1a to terminate seizures. Disrupting mouse ASIC1a increased the severity of chemoconvulsantinduced seizures, whereas overexpressing ASIC1a had the opposite effect. ASIC1a did not affect seizure threshold or onset, but shortened seizure duration and prevented progression. $\mathrm{CO} 2$ inhalation, long known to lower brain $\mathrm{pH}$ and inhibit seizures, also required ASIC1a to interrupt tonic-clonic seizures. Acidosis activated inhibitory interneurons through ASIC1a, suggesting that ASIC1a might limit seizures by increasing inhibitory tone. These findings identify ASIC1a as a key element in

Address Correspondence to: Michael J. Welsh MD or John Wemmie MD PhD, Howard Hughes Medical Institute, University of Iowa College of Medicine, 500 EMRB, Iowa City, IA 52242, Phone 319335 7619, FAX 319335 7623, email michael-welsh@uiowa.edu, john-wemmie@uiowa.edu.

fAuthors contributed equally.

\section{AUTHOR CONTRIBUTIONS}

AEZ played a key role in generating the hypotheses for ASIC1a involvement in seizures, performed slice and in vivo electrophysiology/ behavioral experiments, assessed seizure threshold, measured brain $\mathrm{pH}$ in response to seizures and $\mathrm{CO}_{2}$, assisted in studies using acutely dissociated neurons, wrote initial manuscript drafts and worked closely with other authors in editing the figures and manuscript. MKS initiated, conceived, performed and interpreted electrophysiological experiments in dissociated neurons and assisted in preparation of the manuscript. MAS helped perform and interpret EEG experiments. GWA assisted with seizure threshold studies. MAH provided EEG equipment and helped with EEG interpretation. MJW provided important overall direction and initiation for the project, contributed to experimental design and data interpretation, provided funding, and wrote the manuscript. JAW initiated development of the project, led experimental direction, interpreted data, performed pilot experiments, provided funding, and wrote the manuscript. 
seizure termination when brain $\mathrm{pH}$ falls. The results suggest a molecular mechanism for how the brain stops seizures and suggest new therapeutic strategies.

\section{Keywords}

ASIC1a; seizure; termination; acidosis; epilepsy; $\mathrm{pH}$

\section{INTRODUCTION}

Investigators have discovered many gene disruptions and mutations that predispose humans and mice to seizures ${ }^{1}$. That work has identified numerous ion channels and other proteins that prevent seizure onset or initiation. In contrast, surprisingly little is known about how the brain limits seizure duration and terminates seizures 2,3 . This is despite the consequences of a failure to stop seizures, as in status epilepticus, which can damage the brain and is often fatal.

Multiple mechanisms might stop seizures. One possibility is that seizures deplete factors required for neuron firing. Supporting this possibility, seizures can reduce oxygen, glucose, and metabolic substrates required for neurotransmission 4,5 . However, the role these factors play remains uncertain. While some studies suggest that depleting oxygen, glutamate and ATP can interrupt seizure-like activity 6,7 , other work suggests reduced levels of these factors might initiate and worsen seizures 8,9 . Furthermore, in status epilepticus, seizures can persist for hours, suggesting that prolonged seizures do not exhaust the fuel that sustains them.

Another possibility is that seizures produce inhibitory factors that block continued seizure activity. Protons are an inhibitor that accumulates during seizures. Seizures can reduce brain $\mathrm{pH}$ from $\sim 7.35$ to $6.8^{10,11}$ through lactic acid production, $\mathrm{CO}_{2}$ accumulation, and other mechanisms ${ }^{12}$. Acidosis was first implicated in seizure inhibition in 1929 when Lennox discovered that hypercarbic acidosis eliminated seizure discharges in patients with epilepsy 13 , a finding verified by others 14,15 . Similarly, in brain slices acidosis interrupts seizurelike epileptiform activity ${ }^{16}$. Interestingly, some anticonvulsants, such as acetazolamide, reduce extracellular $\mathrm{pH}$ in the brain, suggesting that acidosis might contribute to their antiepileptic effects.

How acidosis inhibits seizures likely involves multiple mechanisms. For example, extracellular acidosis inhibits NMDA receptors 17 , and NMDA receptor antagonists attenuated acid's effect on epileptiform activity in brain slices 16 . A reduced extracellular $\mathrm{pH}$ also inhibits voltagegated $\mathrm{Na}^{+}$and $\mathrm{Ca}^{2+}$ channels and modulates $\mathrm{GABA}_{\mathrm{A}}$ receptors ${ }^{18}$. Recent data also suggest that extracellular acidosis increases the concentration of extracellular adenosine, which activates adenosine (A1) receptors and ATP (P2X and P2Y) receptors to reduce seizure-like activity in brain slices ${ }^{19}$.

The ability of extracellular acidosis to activate the acid-sensing ion channels (ASICs) suggests these proteins might also mediate effects of $\mathrm{pH}$ on seizures. ASICs are proton-gated members of the degenerin/epithelial $\mathrm{Na}^{+}$channel family ${ }^{20}$. At least three ASICs, ASIC1a, $-2 \mathrm{a}$, and $-2 \mathrm{~b}$, which form homo- and heteromultimeric channels, are widely expressed in the central nervous system (CNS) $20-25$. ASIC1a homomeric channels are activated by protons and conduct $\mathrm{Na}^{+}$and $\mathrm{Ca}^{2+}$ with an EC50 of $\sim 6.823,26,27$. In CNS neurons, ASIC1a is required to generate a current response to $\mathrm{pH}$ values between 7.2 and 5.0 24, 28, 29, and extracellular acidosis activates ASICs to initiate neuron firing 30,31 . Thus ASIC1a may be critical for mediating the brain's response to acidosis. An earlier study showing that inhibitory interneurons had larger $\mathrm{H}^{+}$-gated currents than excitatory neurons ${ }^{32}$, suggested that ASICs might dampen excitability under some conditions. 
Based on the known fall in extracellular $\mathrm{pH}$ during seizures, the ability of acidosis to stop seizures, and the $\mathrm{pH}$-sensitivity of ASIC1a, we hypothesized that ASIC1a might contribute to seizure termination and thereby reduce seizure severity.

\section{RESULTS}

\section{ASIC1a disruption increases seizure severity}

To learn whether ASICla affects seizure severity, we injected wild-type and $\mathrm{SSICla}^{-/-}$mice with kainate, a chemoconvulsant that activates glutamate receptors. During the first $20 \mathrm{~min}$ after injection, mice of both genotypes had similar seizures affecting the head or forelimbs (Fig. 1a). However with time, the $\mathrm{ASICla}^{-1-}$ mice developed more severe seizures (Fig. 1a, b). We also administered pentylenetetrazole (PTZ), a chemoconvulsant that may have multiple targets 33,34 , and quantified the percentage of mice that developed generalized tonic-clonic seizures (GTCS), as described previously by others 34,35 . The majority of $A S I C l a^{-l-}$ mice developed GTCS, whereas wild-type mice were less likely to have GTCS (Fig. 1c). Thus, with two different chemoconvulsants, loss of ASIC1a increased seizure severity.

We also acutely inhibited ASIC1a in wild-type mice with an intracerebroventricular injection of the ASIC1a antagonist psalmotoxin 1 (PcTx1) ${ }^{36}$; such PcTx1 delivery blocks ASIC1a effects on ischemic stroke ${ }^{29}$ and fear ${ }^{37}$. PcTx 1 increased the incidence of continuous GTCS following kainate injection (Fig. 1d). Similar effects on seizure severity with both ASICla gene disruption and pharmacological blockade suggest that developmental abnormalities were not responsible for the effects in $\mathrm{ASICla}^{-/-}$mice.

\section{ASIC1a overexpression reduces seizure severity}

Finding that ASIC1a disruption enhanced seizure severity suggested that overexpressing the channel might have the opposite effect. To test this prediction, we studied transgenic mice overexpressing ASIC1a via a pan-neuronal synapsin 1 promoter (ASIC $1 a^{\mathrm{Tg}+}$ ) ${ }^{38}$. In these mice, ASIC1a expression is increased throughout the brain, and CNS neurons have larger amplitude acid-evoked currents than wild-type littermates ${ }^{38}$. Because we hypothesized that mice overexpressing ASIC1a would have less severe seizures, we injected ASIC1 $\mathrm{a}^{\mathrm{Tg}+}$ and wild-type mice with kainate and PTZ doses that were higher than those used in the earlier studies. ASIC1a overexpression reduced seizure severity following kainate injection (Fig. 1e, f) and reduced the incidence of GTCS after PTZ injection (Fig. 1g). Coupled with our experiments in $\mathrm{ASICla}^{-/-}$mice, these findings suggest a relationship between the level of ASIC1a expression and the degree of seizure protection.

\section{ASIC1a disruption does not alter seizure threshold}

The effect of ASIC1a on seizure severity raised the question of whether it might also affect seizure onset. We tested this possibility using a common method of threshold analysis, the maximal electroconvulsive seizure threshold test ${ }^{39}$. ASIC1a disruption did not reduce the amount of electrical current necessary to evoke a stereotypic seizure response (Fig. 1h). This result and our subsequent studies suggest that ASIC1a does not play a prominent role in determining seizure threshold.

\section{ASIC1a shortens seizure duration}

To further assess how ASIC1a reduces seizure severity, we examined PTZ-evoked seizures using electroencephalography (EEG) to examine epileptiform discharges while simultaneously monitoring seizures behaviorally. We reasoned that if ASICla inhibited the initiation of seizures, then disrupting ASIC1a would accelerate onset of EEG spike activity and enhance initial seizure severity. On the other hand, if ASIC1a enhanced seizure termination, then 
disrupting ASIC1a would prolong EEG spike activity and increase the likelihood that seizures progress to GTCS or death.

Consistent with a normal seizure threshold, we found that the latency to EEG spike activity was the same in $\mathrm{ASICla}^{-/-}$and wild-type mice (Fig. 2a). In addition, within the first $10 \mathrm{~min}$ following PTZ injection, both wild-type and $\mathrm{ASICla}^{-1-}$ mice had seizures of similar severity characterized by myoclonic jerks (not shown) and a similar number of EEG spike discharges (Fig. 2b). However as the seizures continued, differences between the two genotypes became apparent. In wild-type mice, EEG spikes decreased precipitously following the 10-min time point (Fig. 2b). In contrast, most ASICla $a^{-/-}$mice progressed to tonic-clonic seizures and death (Fig. 2c, d). Surviving $\mathrm{ASICla}^{-/-}$mice continued to have more seizure activity than wild-type mice (Fig. 2b). However, because we could only measure EEG spike activity in surviving animals, we likely underestimate the deficit in seizure termination in $\mathrm{ASICla}^{-/-}$mice.

In wild-type mice, seizures were often followed by a suppression of spike discharges (Fig. 3a). This low-amplitude EEG pattern, called post-ictal depression, has been suggested to result from the factors that cause seizure termination 3, 9, 40. In contrast to wild-type mice, $\mathrm{ASICla}^{-/-}$mice had only brief periods of EEG depression that were interrupted by seizure spikes (Fig. 3a, b). ASIC1a disruption significantly reduced post-ictal depression (Fig. 3c). This loss of an EEG pattern associated with seizure termination is consistent with the prolonged seizure activity and the increased severity observed in $\mathrm{SSICla}^{-/-}$mice.

\section{Termination of seizure-like activity by low pH depends on ASIC1a}

We hypothesized that a reduced $\mathrm{pH}$, which is known to occur during seizures, would terminate seizures through ASIC1a. We tested this hypothesis using a hippocampal slice model in which hypomagnesemia induces epileptiform activity ${ }^{16}$. In this model, low $\mathrm{pH}$ is known to inhibit seizure-like activity in the hippocampus ${ }^{16}$, and ASIC1a is expressed in hippocampal neurons 28 . Before inducing seizures, we saw no epileptiform activity in slices of either genotype (Fig. 4a). At $\mathrm{pH} 7.35$, both genotypes showed a similar latency to the onset of epileptiform activity (Fig. 4b, c), and had an equivalent number of epileptiform spikes (Fig. 4b, d). However, when we reduced $\mathrm{pH}$ to 6.8 , seizure activity decreased in wild-type slices, but not in slices from $\mathrm{ASICla}^{-/}$mice. These data suggest that ASIC1a expression is required for the antiepileptic effects of low $\mathrm{pH}$.

\section{Inhibitory interneurons have ASIC currents}

One potential mechanism by which acidosis-induced ASIC currents could inhibit epileptiform discharges would be through their activation of inhibitory interneurons, a cell population that plays a critical role in limiting epileptiform activity. Therefore, we examined the effects of physiologically relevant reductions in $\mathrm{pH}$ on acutely dissociated hippocampal interneurons, as well as excitatory pyramidal neurons. Neurons were identified based on their location (lacunosum moleculare $v s$. CA1), size, morphology, and firing pattern 32,41 . There were four main findings. a) Reducing extracellular $\mathrm{pH}$ activated inward current in wild-type, but not $\mathrm{ASICla}^{-/-}$interneurons (Fig. 5a), a result that agrees with previous studies showing that disrupting ASICla eliminated currents evoked by pH reductions to as low as $5.024,28,29$. b) Reducing pH from 7.4 to values of 7.2, 7.0, and 6.8, evoked ASIC currents (Fig. 5b). These $\mathrm{pH}$ values are in the range reported in seizures 10,11 and in the range we measured (see below). c) We found that interneurons had larger $\mathrm{H}^{+}$-gated current densities than pyramidal neurons (Fig. 5b). Inhibitory interneurons in the rat are also reported to possess larger acid-evoked currents than excitatory neurons ${ }^{32}$.d) When we reduced extracellular $\mathrm{pH}$, we stimulated action potential firing in inhibitory neurons; $\mathrm{pH} 6.8$ induced firing in $78 \%$ of inhibitory neurons $(\mathrm{n}=$ 9 ), and $\mathrm{pH} 7.0$ induced firing in $80 \%$ of the interneurons $(\mathrm{n}=5)$ (Fig. 5c shows an example). 


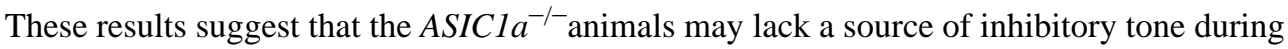
central acidosis, and as a result they fail to inhibit seizure activity.

\section{$\mathrm{CO}_{2}$ inhalation requires $\mathrm{ASIC1a}$ to interrupt seizures}

Almost 80 years ago, Lennox reported that inhaling $\mathrm{CO}_{2}$ inhibited seizures in humans 13 . Subsequent studies demonstrated that $\mathrm{CO}_{2}$ reduces cortical $\mathrm{pH}$ within seconds of inhalation 42,43 , and that breathing $\mathrm{CO}_{2}$ increases brain acidosis during a PTZ-evoked seizure ${ }^{11}$. Thus, we reasoned that inducing hypercarbic acidosis would provide an in vivo test of whether ASIC1a was required for the antiepileptic effects of acidosis. We administered a high dose of PTZ to evoke lethal seizures in animals of both genotypes (Fig. 6a). In separate groups of animals, we switched from air to $10 \% \mathrm{CO}_{2}$ immediately after the onset of tonic-clonic seizures (Fig. 6b). Remarkably, $10 \% \mathrm{CO}_{2}$ prevented lethal seizures in wild-type mice, but had little effect in $\mathrm{ASICla}^{-/-}$mice; in these mice, seizures continued to progress rapidly to death. All of the $\mathrm{ASICla}^{+/+}$mice survived until we switched from $\mathrm{CO}_{2}$ back to air at minute 15 . They then rapidly died.

To verify that brain $\mathrm{pH}$ drops in vivo during seizures and $\mathrm{CO}_{2}$ inhalation, we implanted a fiber optic $\mathrm{pH}$ sensor into the lateral cerebral ventricle of wild-type and $\mathrm{ASICla^{-1- }}$ mice.

Generalized seizures caused brain $\mathrm{pH}$ to fall ( $\mathrm{pH} \sim 7.05$ ) (Fig. 6c, d). $\mathrm{CO}_{2}$ inhalation rapidly and reversibly lowered $\mathrm{pH}$ even further in the seizing mice $(\mathrm{pH} \sim 6.9$ ). Importantly, these are $\mathrm{pH}$ levels that elicit robust ASIC1a currents and firing in inhibitory neurons. Brain $\mathrm{pH}$ fell to similar levels in mice of both genotypes. Together, these results suggest that ASIC1a also mediates the anti-epileptic effects of low $\mathrm{pH}$ in vivo.

\section{DISCUSSION}

Our findings suggest a model in which seizure termination depends on ASIC1a. Seizures reduce extracellular $\mathrm{pH}$ 10,11. Extracellular acidosis, in turn, activates ASIC1a, which terminates seizure activity. Several experiments support the key features of this model. We found that seizures lowered brain $\mathrm{pH}$, as previously reported ${ }^{10,11}$. In addition to the acidosis generated by seizures, we also directly lowered extracellular $\mathrm{pH}$ in vitro and tested hypercarbic acidosis in vivo; both stopped seizure activity in an ASICla-dependent manner. We obtained similar results using three different chemoconvulsants (kainate, PTZ, and a reduced $\mathrm{Mg}^{2+}$ concentration). Finally, disrupting the ASICla gene or pharmacologically inhibiting ASIC1a increased seizure severity, whereas overexpressing ASIC1a had the opposite effect. These findings suggest that ASIC1a forms part of a feedback inhibition system that limits seizure severity.

The data indicate that ASIC1a reduced seizures by enhancing their termination. First, the duration of seizure activity measured by EEG was shorter in wild-type than $\mathrm{ASICla}^{-1-}$ mice. Second, in wild-type mice, seizures were less likely to progress to tonic-clonic seizures and death. Third, ASIC1a increased post-ictal depression of spike wave discharges, which coincides with and is thought to result from endogenous termination mechanisms $3,9,40$. Fourth, ASIC1a disruption did not affect seizure threshold, the latency to seizure onset, or initial seizure severity, suggesting that ASIC1a did not contribute to seizure initiation.

Predicting how ion channel dysfunction precipitates a phenomenon as complex as seizures has proven difficult ${ }^{44}$. Even less is known about the mechanisms that stop seizures. Our findings that reducing $\mathrm{pH}$ to values that occur during seizures evoked ASIC currents and triggered action potential firing in inhibitory neurons suggest that ASICs might trigger inhibitory neuron activity to terminate seizures. However, there are several types of inhibitory neurons and their relative importance in seizure termination and the contribution of ASIC currents to their in vivo activity remain uncertain. Moreover, ASIC channels are also expressed in excitatory 
pyramidal neurons, where they could contribute either to increased activity or reduced activity, perhaps through depolarization blockade. In addition, while we focused on hippocampus, ASIC channels are also expressed in many different brain regions $20,21,37$, and it is possible that ASIC activation of inhibitory neurons in other regions might also contribute to seizure termination. Thus, understanding how ASIC channels influence neuronal circuits to stop seizures suffers from the same complexity that hinders knowledge of how dysfunction of other channels starts seizures. Nevertheless, by identifying ASIC1a as a molecule involved in seizure termination, this work provides an important beginning for further investigation.

In addition to providing a foothold for understanding seizure termination, the ability of ASIC1a to stop seizures may have implications for human seizure disorders and treatment. Recent studies have suggested a role for ASIC1a in mouse models of ischemic stroke ${ }^{29}$, neurodegeneration ${ }^{45}$, and psychiatric disease 37 . Whether ASIC channels are protective or damaging may depend on the magnitude and duration of acidosis, the location of ASIC activation, and the presence of factors that modulate ASIC function, such as lactate 46 . However, the findings described here suggest a new, protective function for ASIC1a in brain physiology. Thus, agents that potentiate ASICla activity might reduce seizure severity or duration and possibly prevent status epilepticus.

\section{MATERIAL AND METHODS}

\section{Mice}

We used age and gender-matched wild-type, $\mathrm{ASICla}^{-/-}$, and $\mathrm{ASICla-overexpressing}$ transgenic (ASIC1a ${ }^{\mathrm{Tg}+}$ ) mice on a congenic C57/B16 background ${ }^{28,38}$. Care of the mice met the standards set forth by the National Institutes of Health and the procedures were approved by the University of Iowa Animal Care and Use Committee.

\section{Convulsants}

Kainate or pentylenetetrazole (PTZ) (Sigma-Aldrich, Saint Louis MO) were injected into the peritoneum (IP) following suspension in phosphate buffered saline (Gibco, Carlsbad CA) and titration to $\mathrm{pH} 7.4$ with $0.1 \mathrm{~N} \mathrm{NaOH}^{35}$.

\section{Behavioral Assays}

To score the effects of ASIC1a on seizure severity in response to kainate we used the Racine ${ }^{47}$ seizure scale: (0) No response, (1) staring/reduced locomotion, (2) activation of extensors/rigidity, (3) repetitive head and limb movements, (4) sustained rearing with clonus, (5) loss of posture, (6) status epilepticus/death. To assess the effects of ASIC1a on seizure severity in response to PTZ we scored the incidence of generalized tonic-clonic seizures (GTCS), which were identified by generalized clonus followed by tonic hind limb extension

34 . We chose different kainate and PTZ doses to test specific hypotheses, to decrease the overall number of animals required, and to avoid ceiling and floor effects. For example, to test the hypothesis that the $\mathrm{ASICla}{ }^{-/-}$mice have more severe seizures than controls, we used a PTZ dose $(50 \mathrm{mg} / \mathrm{kg})$ that would evoke generalized, tonic-clonic seizures in a small percentage of the control wild-type mice. The opposite was true for the experiments with the ASICla transgenic mice; to efficiently test the hypothesis that transgenics have less severe seizures, we used a PTZ dose $(65 \mathrm{mg} / \mathrm{kg})$ that evoked generalized, tonic-clonic seizures in a large percentage of the control, wild-type mice. A trained observer blinded to genotype scored seizure severity. 


\section{PcTx1 administration}

Left-lateral, intracerebroventricular (ICV) guide cannulae were implanted in anesthetized mice (relative to bregma: anteroposterior $-0.3 \mathrm{~mm}$, lateral $-1.0 \mathrm{~mm}$, ventral $-3.0 \mathrm{~mm}$ ). Three to five days later, we injected $5 \mu \mathrm{L}$ of PcTx1-containing venom (SpiderPharm, Yarnell, AZ) (9 ng/ $\mu \mathrm{L}$ ) in ACSF (in mM: $\mathrm{NaCl} 124, \mathrm{KCl} 3, \mathrm{NaH}_{2} \mathrm{PO}_{4} 1.2, \mathrm{MgSO}_{4} 1.2, \mathrm{CaCl}_{2} 2, \mathrm{NaHCO}_{3} 26$ ) or ACSF alone into wild-type mice using a $10 \mu \mathrm{L}-$ Hamilton syringe connected to a 30-gauge injector (over $10 \mathrm{~s}$ ). Two hours later, mice were injected with kainate $(20 \mathrm{mg} / \mathrm{kg}$, IP). Following convulsant injection, mouse behavior was scored as above. Continuous, tonic-clonic seizures were identified by tonus and clonus in all four limbs with loss of posture lasting greater than $60 \mathrm{~s}$. Cannula placement was verified by methylene blue injection after euthanasia.

\section{Testing maximal electroconvulsive seizure (MES) threshold}

Seizure threshold in response to an electrical stimulus was determined as described previously 39 in $\mathrm{ASICla}^{+/+}$and $\mathrm{ASICla}{ }^{-/-}$mice. Electroshock was delivered $(0.2 \mathrm{~s}, 60 \mathrm{~Hz}$, maximal voltage $500 \mathrm{~V}$ ) using the Rodent Shocker-type 221 (Harvard Apparatus, Holliston, MA) with ear electrodes moistened with saline. The occurrence of generalized seizures with sustained hind limb extension was assessed 39 .

\section{EEG Recordings and Analysis}

Two, $3.2 \mathrm{~mm}$ stainless steel screws (Stoelting, Wood Dale IL) were stereotactically implanted under ketamine/xylazine anesthesia above the left frontal lobe and cerebellum; these electrodes served as an epidural recording and reference/ground electrodes respectively (frontal: anteroposterior $+1.5 \mathrm{~mm}$, lateral $-1.5 \mathrm{~mm}$; cerebellum reference: anteroposterior $-6.0 \mathrm{~mm}$ ). Mice recovered from surgery for at least 1 week, and EEG activity was recorded by tethered connecting leads from freely moving mice in a sound-attenuated chamber. EEG was recorded at baseline and in response to a single IP injection of PTZ $(50 \mathrm{mg} / \mathrm{kg})$ in $\mathrm{ASICla}^{+/+}$and $A S I C l a^{-1-}$ mice. During the 30 min following injection, tonic-clonic and lethal seizures were identified behaviorally and electrographically by simultaneous video and EEG monitoring. EEG was captured using a TDT MEDUSA preamplifier and base-station and recorded at a sampling rate of $508.6 \mathrm{~Hz}$ with TDT OpenX software with high and low pass filters at $2 \mathrm{~Hz}$ and $70 \mathrm{~Hz}$ respectively. EEG recordings were analyzed using Origin 7.5 software by an experimenter blinded to genotype. Latency to seizure onset was defined as the time from injection to first seizure spike. Seizure spikes were detected using the peak analysis function of Origin v7.5. Major seizure events and sharply delimited seizure spikes exceeding twice the baseline amplitude were scored.

Post-ictal depression was defined as a low-amplitude, slow-wave EEG signal without seizure spikes occurring after a seizure ${ }^{40}$. The duration of post-ictal depression was defined from its onset following a seizure until the resumption of seizure spikes or return of the EEG signal to an amplitude exceeding $2 \mathrm{mV}^{40}$. Based on seizure severity and the longest observed period of post-ictal suppression, each mouse was scored and separated into one of 5 categories: (1) no post-ictal depression and lethal seizures, (2) no post-ictal depression with persistent seizure activity, (3) depression < 60 seconds, (4) depression $=60-180$ seconds, (5) depression $>180$ seconds.

\section{Slice recordings and analysis}

Horizontal hippocampal slices $(400 \mu \mathrm{m})$ were prepared from 14 to $24-$ day-old $A S I C 1 a^{+/+}$and $\mathrm{ASICla}^{-1-}$ mice similar to methods described 28,48 . Prior to sectioning, the mice were transcardially perfused with a high $\mathrm{Mg}^{2+} /$ low $\mathrm{Ca}^{2+}$ solution chilled to $4{ }^{\circ} \mathrm{C}$ (in $\mathrm{mM}$ ): 4.9 $\mathrm{MgSO}_{4}, 0.5 \mathrm{CaCl}_{2}, 126 \mathrm{NaCl}, 5 \mathrm{KCl}, 1.25 \mathrm{NaH}_{2} \mathrm{PO}_{4}, 27.7 \mathrm{NaHCO}_{3}, 10$ dextrose, 1.1 $\mathrm{MgCl}_{2}, \mathrm{pH} 7.35$ bubbled with $95 \% \mathrm{O}_{2} / 5 \% \mathrm{CO}_{2}$. After sectioning, slices were incubated in 
artificial cerebral spinal fluid (ACSF) for at least 1 hour prior to testing: $126 \mathrm{NaCl}, 5 \mathrm{KCl}, 1.8$ $\mathrm{MgSO}_{4}, 1.25 \mathrm{NaH}_{2} \mathrm{PO}_{4}, 27.7 \mathrm{NaHCO}_{3}, 10$ dextrose, and $1.6 \mathrm{CaCl}_{2}$. Standard extracellular field potential recording techniques were performed in a submerged chamber perfused with ACSF (flow-rate $4 \mathrm{ml} / \mathrm{min}, 33 \pm 0.5{ }^{\circ} \mathrm{C}$ ). Field-potentials were recorded in the proximal CA3 hippocampal field with ACSF-filled glass pipettes $(<5 \mathrm{M} \Omega)$. To evoke seizure activity, normal ACSF was replaced with ACSF minus $\mathrm{MgSO}_{4}$. Latency to onset of epileptiform activity was defined as the time elapsed between switching to nominal $\mathrm{Mg}^{2+}$ ACSF until the first epileptiform spike. After scoring the latency to epileptiform activity and recording $5 \mathrm{~min}$ of seizure activity, $\mathrm{pH}$ was reduced to 6.8 by lowering $\mathrm{NaHCO}_{3}$ concentration to $11.4 \mathrm{mM}$, and increasing sodium gluconate to $16.3 \mathrm{mM}$ to maintain osmolarity. $\mathrm{pH}$ in the recording chamber was measured both prior to and during infusion of $\mathrm{pH} 6.8$ ACSF. The effects of low $\mathrm{pH}$ were then recorded for $5 \mathrm{~min}$, and $\mathrm{pH}$ was then switched back to 7.35. Slices that failed to develop ictal discharges were excluded ( $40 \%$ of $\mathrm{ASICla}^{+/+}$slices, $\mathrm{n}=15$, and $38 \%$ of $\mathrm{ASICla}^{-/-}$slices, $\mathrm{n}=13$ ). To quantify epileptiform activity, we used a method similar to that described by others 49. Using the threshold function in Clampfit v9.2 we quantified the total number of seizure spikes during three 4.5-min time windows occurring immediately before, during, and after dropping $\mathrm{pH}$ to 6.8 . The 30 seconds required to completely change the bath solution to $\mathrm{pH} 6.8$ were excluded from the analysis. A threshold was chosen for each slice that would detect seizure spikes, and not single-unit activity. The average thresholds were similar between genotypes $\left(\right.$ ASICla $^{+/+}=0.355 \pm 0.032 \mathrm{mV} ;$ ASICla $\left.^{-/-}=0.305 \pm 0.04 \mathrm{mV}\right)$. When slices were challenged repeatedly with low $\mathrm{pH}$, the trials were pooled to calculate a mean number of discharges for each condition.

\section{Whole cell electrophysiology}

Acutely dissociated neurons were isolated from age 8-12 day old $\mathrm{ASICla}^{+/+}$and $\mathrm{ASICla}^{-/-}$ mice according to an established protocol ${ }^{50}$. Mice were anesthetized (isoflurane), decapitated, and $500 \mu \mathrm{M}$ coronal sections were cut with a vibratome in ice-cold PIPES buffered saline (115 $\mathrm{mM} \mathrm{NaCl}, 5 \mathrm{mM} \mathrm{KCl}, 20 \mathrm{mM}$ PIPES, $1 \mathrm{mM} \mathrm{CaCl}_{2}, 4 \mathrm{mM} \mathrm{MgCl}_{2}$, D-glucose 25, pH 7.0 with $\mathrm{NaOH})$ in the presence of $100 \% \mathrm{O}_{2}$. CA1 and the lacunosum moleculare layer (LM) of the hippocampus were removed by microdissection and trypsin digested $(15 \mathrm{mg})$ for $30 \mathrm{~min}$ at 30 ${ }^{\circ} \mathrm{C}$ in $20 \mathrm{ml}$ PIPES saline. Tissue was washed three times in PIPES saline and triturated in 0.5 $\mathrm{ml}$ PIPES saline with Pasteur pipettes of decreasing apertures to dissociate neurons. Neurons were then diluted in $8 \mathrm{ml}$ Dulbecco's modified Eagle's medium with $25 \mathrm{mM}$ HEPES, $25 \mathrm{mM}$ glucose (Gibco), 5\% horse serum and placed on $10 \mathrm{~mm}$ glass cover slips (poly-D-lysine/ laminin, BD Biosciences) in 24 well plates at $37^{\circ} \mathrm{C}$. Neurons were studied in voltage-clamp and current-clamp modes within 1 to $5 \mathrm{~h}$ as previously described ${ }^{37}$. In brief, neurons were superfused in bath solutions containing (in $\mathrm{mM}$ ) $145 \mathrm{NaCl}, 5.4 \mathrm{KCl}, 2 \mathrm{CaCl}_{2}, 1 \mathrm{MgCl}_{2}, 10$ HEPES, $10 \mathrm{MES}$ and $\mathrm{pH}$ was adjusted with TMA.OH. Pipettes (3-5 M $\omega$ polished glass pipettes (Drummond Scientific, $100 \mu \mathrm{l}$ )) contained (in $\mathrm{mM}$ ) $5 \mathrm{NaCl}, 90 \mathrm{~K}$-gluconate, $15 \mathrm{KCl}, 1$ $\mathrm{MgCl}_{2}, 10$ EGTA, $60 \mathrm{HEPES}$, and $3 \mathrm{Na}_{2} \mathrm{ATP}$, adjusted to $\mathrm{pH} 7.3$ with $\mathrm{KOH}$. Extracellular $\mathrm{pH}$ was switched with a Rapid Solution Changer (RSC-200; Biologic, Grenoble, France). In voltage-clamp mode, membrane potential was maintained at $-70 \mathrm{mV}$. In current-clamp, holding voltage was adjusted to $-77 \pm 2 \mathrm{mV}$. Inhibitory neurons were identified by: location (lacunosum moleculare layer microdissection), round morphology, and size $(4.4 \pm 0.3 \mu \mathrm{m})$

32, 41 . Excitatory, pyramidal neurons were identified by: location (CA1 microdissection), pyramidal morphology, spike frequency adaptation in response to current injection, and size $(8.3 \pm 0.3 \mu \mathrm{m})$.

\section{Testing the anti-epileptic effects of $\mathrm{CO}_{2}$}

$\mathrm{ASICla}^{+/+}$and $\mathrm{ASICla}^{-/-}$mice were injected IP with $90 \mathrm{mg} / \mathrm{kg}$ PTZ. After the onset of generalized-clonic seizures, compressed air or $10 \% \mathrm{CO}_{2}$ (in air) was rapidly administered in an airtight Plexiglas chamber for $15 \mathrm{~min}$. Generalized clonic-seizures were identified 
behaviorally by clonus in all four limbs. The percentage of surviving mice was plotted during each min of the trial. After $30 \mathrm{~min}$, surviving mice were euthanized.

\section{Measuring brain $\mathrm{pH}$}

Age (13-15 weeks) and gender-matched $\mathrm{ASICla}^{+/+}$and $\mathrm{ASICla}^{-/-}$mice were anesthetized with ketamine/xylazine. 60 min after sedation, a fiber optic $\mathrm{pH}$ sensor (pHOptica, Sarasota, FL) was placed in the left lateral ventricle (coordinates above). The sensor was calibrated at $35^{\circ} \mathrm{C}$ and $\mathrm{pH}$ values were calculated using pHOptica-v1.0 software, taking care to input the mouse core temperature under anesthesia. Following 5 min of baseline $\mathrm{pH}$ measurement, we injected PTZ (IP). We found that due to the anesthesia, a high dose $(120 \mathrm{mg} / \mathrm{kg})$ of convulsant was required to achieve an approximate level of seizure activity seen in unanesthetized mice. In the event that generalized seizure activity did not occur, an additional $60 \mathrm{mg} / \mathrm{kg}$ was injected every 20 min until generalized seizures began. The total amount of convulsant administered did not significantly differ between two genotypes $\left(\right.$ ASICla $^{+/+}=252 \pm 34.9 \mathrm{mg} / \mathrm{kg}$, ASICla $^{-l-}=216 \pm 14.7 \mathrm{mg} / \mathrm{kg}$ ).

During $\mathrm{pH}$ measurements, mice were continuously exposed to compressed air. Following the onset of generalized seizure activity, brain $\mathrm{pH}$ dropped to a stable level below 7.1 (see results). At that time, we administered $10 \% \mathrm{CO}_{2}$ for at least 5 min. Following $\mathrm{CO}_{2}$ administration, air was administered for an additional $10 \mathrm{~min}$. The baseline brain $\mathrm{pH}$, minimum $\mathrm{pH}$ during seizure, and minimum $\mathrm{pH}$ during $\mathrm{CO}_{2}$ administration were assessed.

\section{Statistics}

Values are expressed as mean \pm s.e.m. Where indicated, analyses of significance were performed using the unpaired t-test or ANOVA to compare two groups at multiple time points or $\mathrm{pH}$ values. For ANOVA, current density data were transformed to $\log _{10}$ values. The MannWhitney U-test (Wilcoxon rank sum) was used to compare two groups of ordinal variables. The Fisher's exact test was used to compare two groups of two categorical variables. KaplanMeier analysis and Mantel-Cox log rank were used to assess survival. Probit analysis with $95 \%$ confidence intervals was used to calculate the CD50 in threshold experiments. P-values less than 0.05 were considered statistically significant (Microsoft Excel, SPSS).

\section{Acknowledgements}

We would like to thank Jill M. Haenfler and Amanda Wunsch for excellent technical assistance, Douglas R. Langbehn and Bridget Zimmerman for assisting with statistical analysis, Christopher K. Kovach for assistance with EEG equipment and analysis, Francois Abboud and Vladislav Snitsarev for assistance with EEG computational analysis. AEZ was supported by the University of Iowa Interdisciplinary Training Program in Pain Research NINDS T32NS045549. MJW is an Investigator of the Howard Hughes Medical Institute. JAW was supported by NINDS 1R21NS058309-01A1, Veteran's Administration Advanced Career Development Award, and a Research Initiatives grant from the University of Iowa Roy J. and Lucille A. Carver College of Medicine.

\section{References}

1. Noebels JL. The biology of epilepsy genes. Annu Rev Neurosci 2003;26:599-625. [PubMed: 14527270]

2. Spencer SS, Spencer DD. Implications of seizure termination location in temporal lobe epilepsy. Epilepsia 1996;37:455-458. [PubMed: 8617174]

3. Bragin A, Penttonen M, Buzsaki G. Termination of epileptic afterdischarge in the hippocampus. J Neurosci 1997;17:2567-2579. [PubMed: 9065516]

4. Chapman AG, Meldrum BS, Siesjo BK. Cerebral metabolic changes during prolonged epileptic seizures in rats. J Neurochem 1977;28:1025-1035. [PubMed: 16986]

5. Freund TF, Buzsaki G, Prohaska OJ, Leon A, Somogyi P. Simultaneous recording of local electrical activity, partial oxygen tension and temperature in the rat hippocampus with a chamber-type 
microelectrode. Effects of anaesthesia, ischemia and epilepsy. Neuroscience 1989;28:539-549. [PubMed: 2710329]

6. Kloiber O, Bockhorst K, Hoehn-Berlage M, Hossmann KA. Effect of hypoxia on bicuculline seizures of rat: NMR spectroscopy and bioluminescence imaging. NMR Biomed 1993;6:333-338. [PubMed: 8268066]

7. Yamada K, et al. Protective role of ATP-sensitive potassium channels in hypoxia-induced generalized seizure. Science 2001;292:1543-1546. [PubMed: 11375491]

8. Kirchner A, Veliskova J, Velisek L. Differential effects of low glucose concentrations on seizures and epileptiform activity in vivo and in vitro. Eur J Neurosci 2006;23:1512-1522. [PubMed: 16553614]

9. Haglund MM, Schwartzkroin PA. Role of Na-K pump potassium regulation and IPSPs in seizures and spreading depression in immature rabbit hippocampal slices. J Neurophysiol 1990;63:225-239. [PubMed: 2313342]

10. Somjen GG. Acidification of interstitial fluid in hippocampal formation caused by seizures and by spreading depression. Brain Res 1984;311:186-188. [PubMed: 6488041]

11. Wang RIHRRS. PH of Cerebral cortex during induced convulsions. J Neurophysiol 1955;18:130137. [PubMed: 14354450]

12. Kaila, K.; Chesler, M. Activity-evoked changes in extracellular pH. In: Kaila, K.; Ransom, BR., editors. pH and Brain Function. 309. Wiley-Liss, Inc; 1998.

13. Lennox WG. The effect on epileptic seizures of varying the composition of the respired air. Journal of Clinical Investigation 1929;VI:23-24.

14. Mitchell WG, Grubbs RC. Inhibition of audiogenic seizures by carbon dioxide. Science 1956;123:223-224. [PubMed: 13298679]

15. Woodbury DM, Rollins LT, Henrie JR, Jones JC, Sato T. Effects of carbon dioxide and oxygen on properties of experimental seizures in mice. Am J Physiol 1956;184:202-208. [PubMed: 13283115]

16. Velisek L, Dreier JP, Stanton PK, Heinemann U, Moshe SL. Lowering of extracellular pH suppresses low- $\mathrm{Mg}(2+)$-induces seizures in combined entorhinal cortex-hippocampal slices. Exp Brain Res 1994;101:44-52. [PubMed: 7843301]

17. Traynelis SF, Cull-Candy SG. Proton inhibition of $N$-methyl-D-aspartate receptors in cerebellar neurons. Nature 1990;345:347-350. [PubMed: 1692970]

18. Somjen, GG.; Tombaugh, GC. pH modulation of neuronal excitability and central nervous system functions. In: Kaila, K.; Ransom, BR., editors. pH and Brain Function. Wiley-Leiss Inc; New York: 1998. p. 373-393.

19. Dulla CG, et al. Adenosine and ATP link PCO2 to cortical excitability via pH. Neuron 2005;48:10111023. [PubMed: 16364904]

20. Waldmann R, Champigny G, Bassilana F, Heurteaux C, Lazdunski M. A proton-gated cation channel involved in acid-sensing. Nature 1997;386:173-177. [PubMed: 9062189]

21. García-Añoveros J, Derfler B, Neville-Golden J, Hyman BT, Corey DP. BNaC1 and BNaC2 constitute a new family of human neuronal sodium channels related to degenerins and epithelial sodium channels. Proc Natl Acad Sci U S A 1997;94:1459-1464. [PubMed: 9037075]

22. Lingueglia $\mathrm{E}$, et al. A modulatory subunit of acid sensing ion channels in brain and dorsal root ganglion cells. J Biol Chem 1997;272:29778-29783. [PubMed: 9368048]

23. Benson CJ, et al. Heteromultimerics of DEG/ENaC subunits form $\mathrm{H}^{+}$-gated channels in mouse sensory neurons. Proc Natl Acad Sci U S A 2002;99:2338-2343. [PubMed: 11854527]

24. Wemmie JA, et al. Acid-sensing ion channel 1 is localized in brain regions with high synaptic density and contributes to fear conditioning. J Neurosci 2003;23:5496-5502. [PubMed: 12843249]

25. Alvarez de la Rosa D, et al. Distribution, subcellular localization and ontogeny of ASIC1 in the mammalian central nervous system. J Physiol 2003;546:77-87. [PubMed: 12509480]

26. Yermolaieva O, Leonard AS, Schnizler MK, Abboud FM, Welsh MJ. Extracellular acidosis increases neuronal cell calcium by activating acid-sensing ion channel 1a. Proc Natl Acad Sci U S A 2004;101:6752-6757. [PubMed: 15082829]

27. Zha XM, Wemmie JA, Welsh MJ. ASIC1a is a postsynaptic proton receptor that influences the density of dendritic spines. Proc Natl Acad Sci USA 2006;103:16556-16561. [PubMed: 17060608] 
28. Wemmie JA, et al. The acid-activated ion channel ASIC contributes to synaptic plasticity, learning, and memory. Neuron 2002;34:463-477. [PubMed: 11988176]

29. Xiong ZG, et al. Neuroprotection in ischemia: blocking calcium-permeable acid-sensing ion channels. Cell 2004;118:687-698. [PubMed: 15369669]

30. Gruol DL, Barker JL, Huang LY, MacDonald JF, Smith TG Jr. Hydrogen ions have multiple effects on the excitability of cultured mammalian neurons. Brain Res 1980;183:247-252. [PubMed: 7357408]

31. Vukicevic M, Kellenberger S. Modulatory effects of acid-sensing ion channels (ASICs) on action potential generation in hippocampal neurons. Am J Physiol Cell Physiol 2004;287:C682-690. [PubMed: 15115705]

32. Bolshakov KV, et al. Characterization of acid-sensitive ion channels in freshly isolated rat brain neurons. Neuroscience 2002;110:723-730. [PubMed: 11934479]

33. Dubberke R, Vasilets LA, Schwarz W. Inhibition of the $\mathrm{Na}^{+}, \mathrm{K}^{+}$pump by the epileptogenic pentylenetetrazole. Pflugers Arch 1998;437:79-85. [PubMed: 9817790]

34. Fisher RS. Animal models of the epilepsies. Brain Res Rev 1989;14:245-278. [PubMed: 2679941]

35. Cole TB, Robbins CA, Wenzel HJ, Schwartzkroin PA, Palmiter RD. Seizures and neuronal damage in mice lacking vesicular zinc. Epilepsy Res 2000;39:153-169. [PubMed: 10759303]

36. Escoubas $\mathrm{P}$, et al. Isolation of a tarantula toxin specific for a class of proton-gated Na+ channels. $\mathrm{J}$ Biol Chem 2000;275:25116-25121. [PubMed: 10829030]

37. Coryell M, et al. Targeting ASIC1a reduces innate fear and alters neuronal activity in the fear circuit. Biol Psychiatry 2007;62:1140-1148. [PubMed: 17662962]

38. Wemmie J, Coryell M, Askwith C, Lamani E, Leonard S, Sigmund C, Welsh M. Overexpression of acid-sensing ion channel 1a in transgenic mice increases fear-related behavior. Proc Natl Acad Sci U S A 2004;101:3621-3626. [PubMed: 14988500]

39. Mares, P.; Kubova, H. Electrical stimulation-induced models of seizures. In: Pitkänen, A.; Schwartzkroin, PA.; Moshé, SL., editors. Models of Seizures and Epilepsy. Elsevier Academic Press; New York: 2006. p. 153

40. Buckmaster PS, Wong EH. Evoked responses of the dentate gyrus during seizures in developing gerbils with inherited epilepsy. J Neurophysiol 2002;88:783-793. [PubMed: 12163530]

41. Freund TF, Buzsaki G. Interneurons of the hippocampus. Hippocampus 1996;6:347-470. [PubMed: 8915675]

42. Tschirgi RD, Taylor JL. Slowly changing Bioelectric Potentials Associated With the Blood-Brain Barrier. Am J Physiol 1958;195:7-22. [PubMed: 13583113]

43. Meduna, LJ. The Physiological basis of carbon dioxide treatment. In: Meduna, LJ., editor. Carbon Dioxide Therapy. Charles C Thomas; Springfield, IL: 1958. p. 10

44. Waxman SG. Channel, neuronal and clinical function in sodium channelopathies: from genotype to phenotype. Nat Neurosci 2007;10:405-409. [PubMed: 17387329]

45. Friese MA, et al. Acid-sensing ion channel-1 contributes to axonal degeneration in autoimmune inflammation of the central nervous system. Nat Med 2007;13:1483-1489. [PubMed: 17994101]

46. Immke DC, McCleskey EW. Lactate enhances the acid-sensing Na+ channel on ischemia-sensing neurons. Nat Neurosci 2001;4:869-870. [PubMed: 11528414]

47. Racine RJ. Modification of seizure activity by electrical stimulation. II Motor seizure. Electroencephalogr Clin Neurophysiol 1972;32:281-294. [PubMed: 4110397]

48. Bernard, C. Models of Seizures and Epilepsy. Elsevier Inc; 2006. Hippocampal slices: Designing and interpreting studies in epilepsy research; p. 59-72.

49. Anderson WW, Swartzwelder HS, Wilson WA. The NMDA receptor antagonist 2-amino-5phosphonovalerate blocks stimulus train-induced epileptogenesis but not epileptiform bursting in the rat hippocampal slice. J Neurophysiol 1987;57:1-21. [PubMed: 2881986]

50. Kay AR, Wong RK. Isolation of neurons suitable for patch-clamping from adult mammalian central nervous systems. J Neurosci Methods 1986;16:227-328. [PubMed: 3523050] 

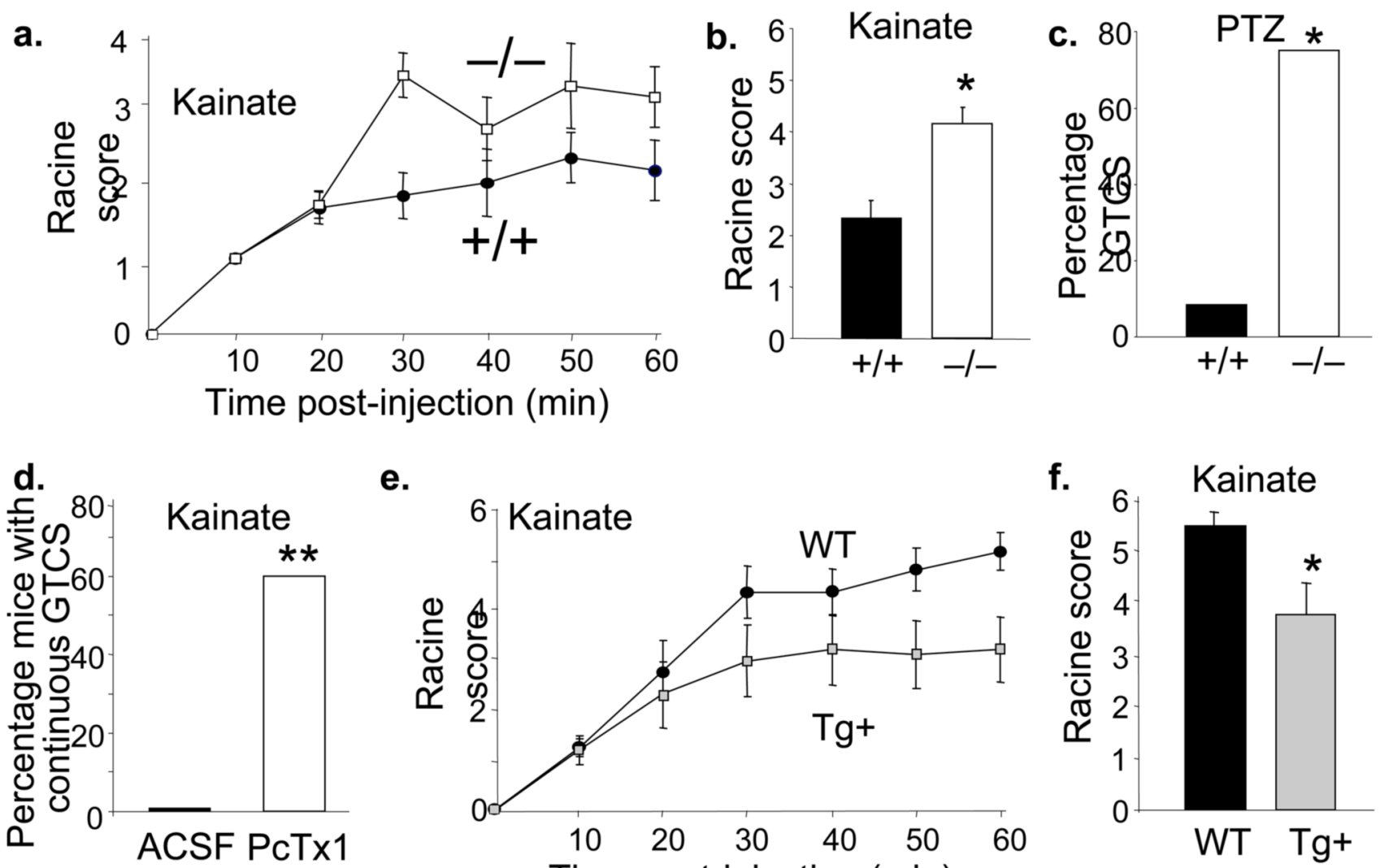

e.

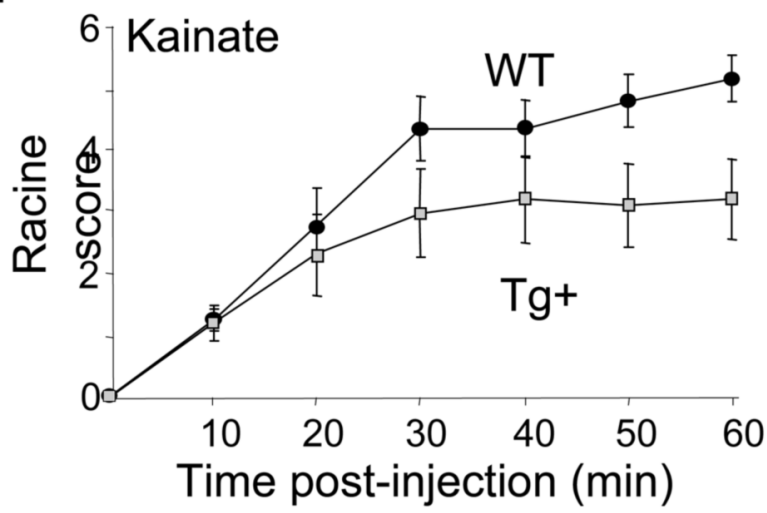

f.

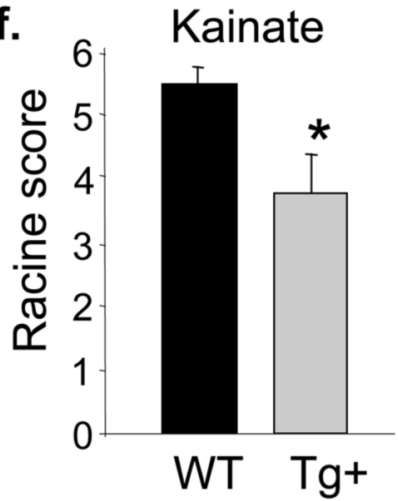

g.

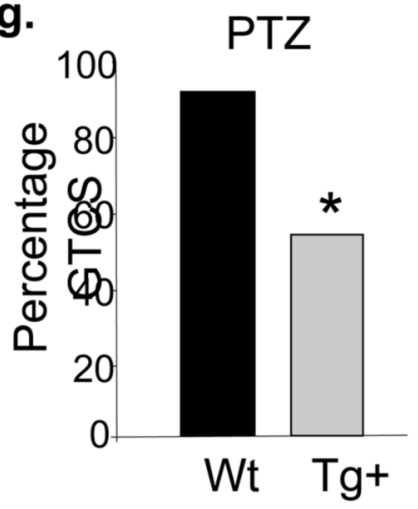

h.

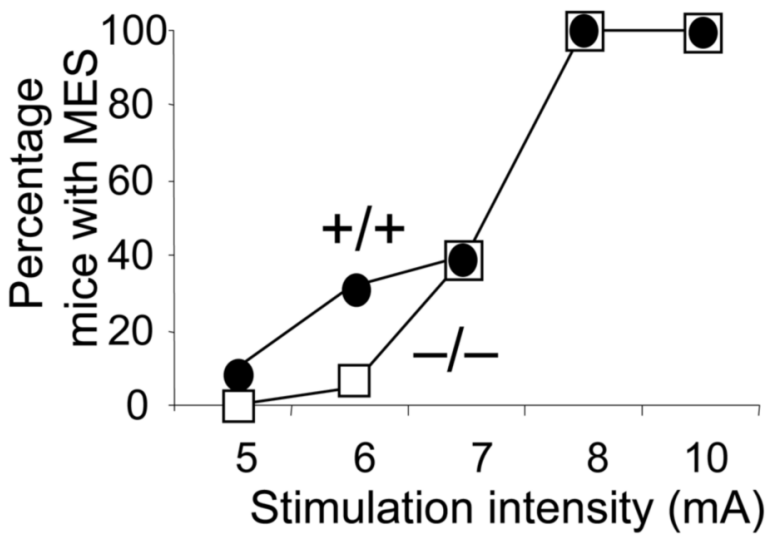

Figure 1.

ASIC1a reduces seizure severity. (a) Seizure response over time in $\mathrm{ASICla}^{+/+}$and ASIC $1 a^{-/-}$mice following kainate injection $(20 \mathrm{mg} / \mathrm{kg}$ IP) $(+/+, \mathrm{n}=6 ;-/-, \mathrm{n}=7$; age 13-22 weeks). For each ten-minute interval, the highest level of seizure activity was scored using the Racine seizure scale (see methods). There was a significant main effect of time $(F(1,6)=27.3$, $\mathrm{p}<0.0001)$ and a significant time $\times$ genotype interaction $(\mathrm{F}(1,6)=2.39, \mathrm{p}=0.039)$ (ANOVA with repeated measures), suggesting that as time passes seizures were likely to become more severe in the $A S I C l a^{-/-}$mice. (b) Maximum Racine score during the 60 minute trial (MannWhitney U test; $* \mathrm{p}=0.004)$. (c) Incidence of generalized tonic-clonic seizures (GTCS) in + / + and $-/-$ mice following PTZ injection $(50 \mathrm{mg} / \mathrm{kg}$ IP) $(+/+, \mathrm{n}=12 ;-/-, \mathrm{n}=8$, age $18-22$ 
weeks; Fisher's exact test; $* \mathrm{p}=0.004)$. (d) Incidence of continuous, tonic-clonic seizures in wild-type mice injected with $5 \mathrm{~mL}$ ACSF (ICV) or PcTx $1(9 \mathrm{ng} / \mathrm{mL}$ ). Treatment with PcTx1 significantly increased the incidence of sustained seizures (ACSF, $n=10 ;$ PcTx $1, n=12$, age 9-11 weeks; Fisher's exact test $* \mathrm{p}=0.005$ ). (e) Seizure response over time in $\mathrm{ASICla}^{+/+}$(WT) and ASIC1a-overexpressing-transgenic ( $\mathrm{Tg}+$ ) mice following $30 \mathrm{mg} / \mathrm{kg}$ IP kainate (WT, $\mathrm{n}=$ $11 ; \mathrm{Tg}+, \mathrm{n}=9$, age 31-36 weeks). With time, seizures were less severe in mice overexpressing ASIC1a (ANOVA with repeated measures; $F(1,3.35)=3.295, p=0.022$ ). (f) Maximum Racine score during the 60 minute trial (Mann-Whitney U test; *p $=0.041$ ). (g) Incidence of generalized tonic-clonic seizures (GTCS) in WT and Tg+ mice following PTZ injection (65 $\mathrm{mg} / \mathrm{kg}$ IP) (WT, $\mathrm{n}=13 ; \mathrm{Tg}+, \mathrm{n}=13$, age 25-41 weeks; Fisher's exact test; *p = 0.037). (h) Occurrence of maximal electroconvulsive seizures (MES) in $\mathrm{ASICla}^{+/+}$and $\mathrm{ASICla}^{-/-}$mice in response to electrical stimulation. ASIC1a disruption did not significantly alter MES threshold $(+/+, \mathrm{n}=50$, CD50 95\% confidence interval $=6.24-7.95 ;-/-, \mathrm{n}=46$, CD50 95\% confidence interval $=6.71-7.76)$. The sample sizes and current intensities were: $5 \mathrm{~mA}$, $\operatorname{ASICla}^{+/+}(\mathrm{n}=11)$ vs. $\operatorname{ASICla}^{-/-}(\mathrm{n}=7) ; 6 \mathrm{~mA}, \operatorname{ASICla}^{+/+}(\mathrm{n}=22)$ vs. $\operatorname{ASICla}^{-/-}(\mathrm{n}=21)$; $7 \mathrm{~mA}, \operatorname{ASICla}^{+/+}(\mathrm{n}=10)$ vs. ASICIa ${ }^{-/-}(\mathrm{n}=10) ; 8 \mathrm{~mA}, \operatorname{ASICla}^{+/+}(\mathrm{n}=4)$ vs. ASICIa $^{-/-}(\mathrm{n}$ $=4) ; 10 \mathrm{~mA}$, ASICla $^{+/+}(\mathrm{n}=3)$ vs. ASICla ${ }^{-/-}(\mathrm{n}=4)$, age 8-22 weeks. 

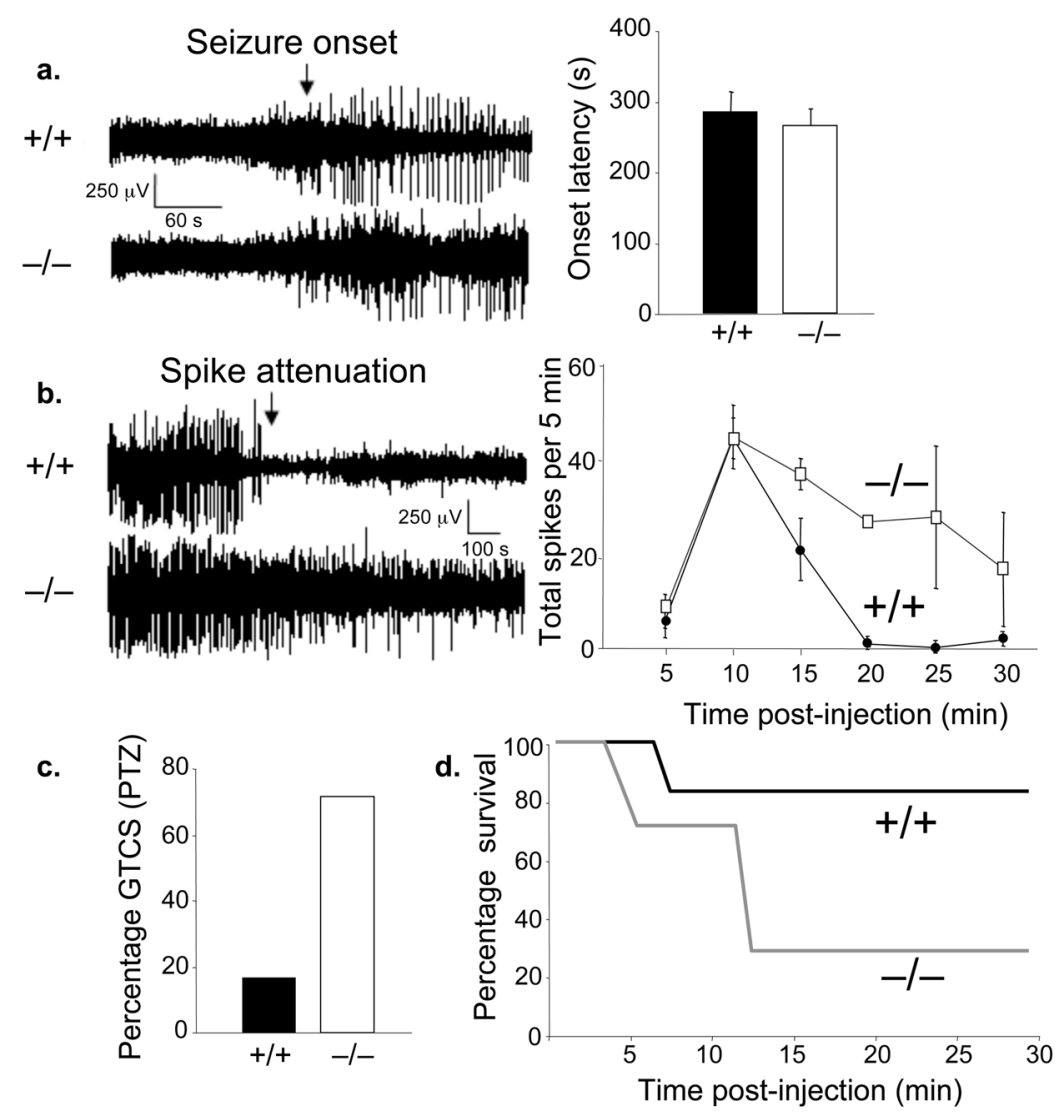

Figure 2.

ASIC1 a disruption increases seizure duration and progression. (a) Representative EEG tracings and quantification of time from PTZ injection $(50 \mathrm{mg} / \mathrm{kg} \mathrm{IP})$ until first seizure spikes in $\mathrm{ASICla}^{+/+}$and $\mathrm{ASICla}^{-/-}$mice $(+/+, \mathrm{n}=6 ;-/-, \mathrm{n}=7$, age 18-22 weeks; unpaired t-test: $\mathrm{t}$ $(11)=0.544, p=0.597$ ). (b) Representative EEG tracings and total number of seizure spikes per five minute interval in surviving mice $\left(+/+, \mathrm{n}=6 ;^{-} /^{-}, \mathrm{n}=7\right)$. Spike number varied significantly with time (Mixed model analysis; $F(1,5)=23.5, \mathrm{p}<0.001$ ), and there was a significant time $\mathrm{x}$ genotype interaction $(\mathrm{F}(1,6)=32.9, \mathrm{p}<0.001)$, suggesting that $A S I C l a^{-/}$mice had prolonged seizure activity as time elapsed. (c) Incidence of generalized tonic-clonic seizures (GTCS) following PTZ injection (50 mg/kg IP) $(+/+, \mathrm{n}=6 ;-/-, \mathrm{n}=7$; Fisher's exact test; $\mathrm{p}=0.078)$. (d) Survival over time (+/+, $n=6 ;-/-, \mathrm{n}=7$; Mantel-Cox Log Rank, $\mathrm{p}=0.025$ ). 


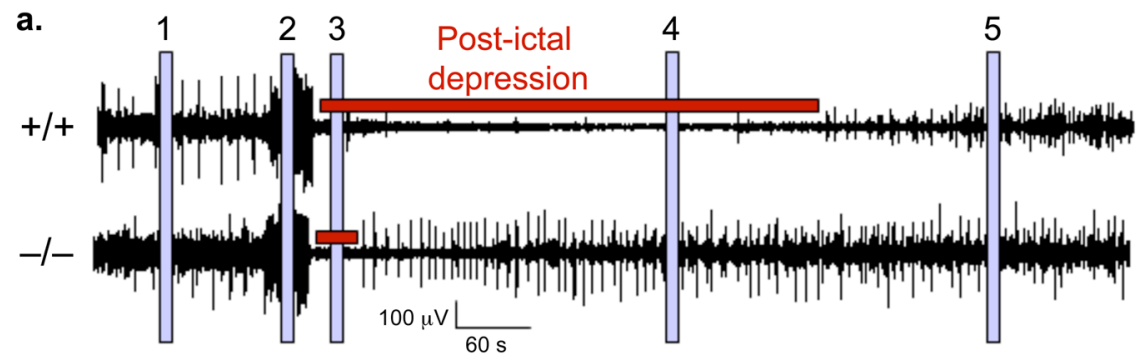

b.

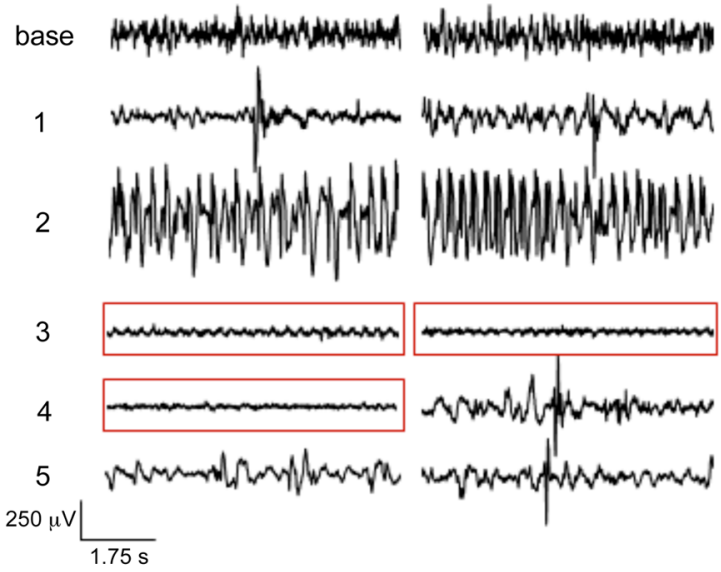

c.

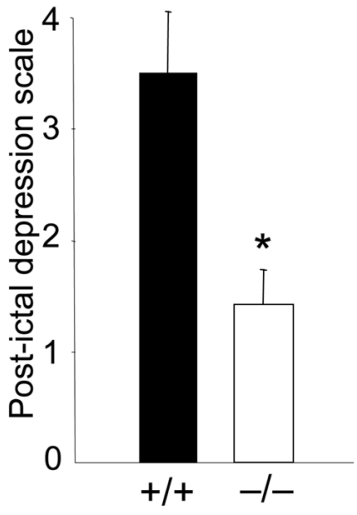

Figure 3.

ASIC1a disruption reduces post-ictal depression. (a) Representative EEG tracings from an $\mathrm{ASICla}^{+/+}$and $\mathrm{ASICla}^{-/-}$mouse approximately $5 \mathrm{~min}$. following PTZ injection $(50 \mathrm{mg} / \mathrm{kg}$ IP). Five, 5-second intervals are denoted by blue vertical bars. These are shown below (b) in rows using an expanded time scale. EEG tracings prior to PTZ injection (base), initial spikewave activity (1), and seizures associated with forelimb clonus (2) were similar in both genotypes. However, immediately following seizures (3), mice entered a period of post-ictal depression (red boxes). Post-ictal depression quickly reverted to seizure activity in $A S I C l a^{-l-}$ mice $(4,5)$. (c) Quantification of post-ictal depression as scored using the postictal depression scale (see methods) (+/+, $\mathrm{n}=6 ;-/-, \mathrm{n}=7$, age 18-22 weeks; Mann-Whitney U test, ${ }^{*} \mathrm{p}=0.011$ ). 
a. pH 7.35 pre-ictal
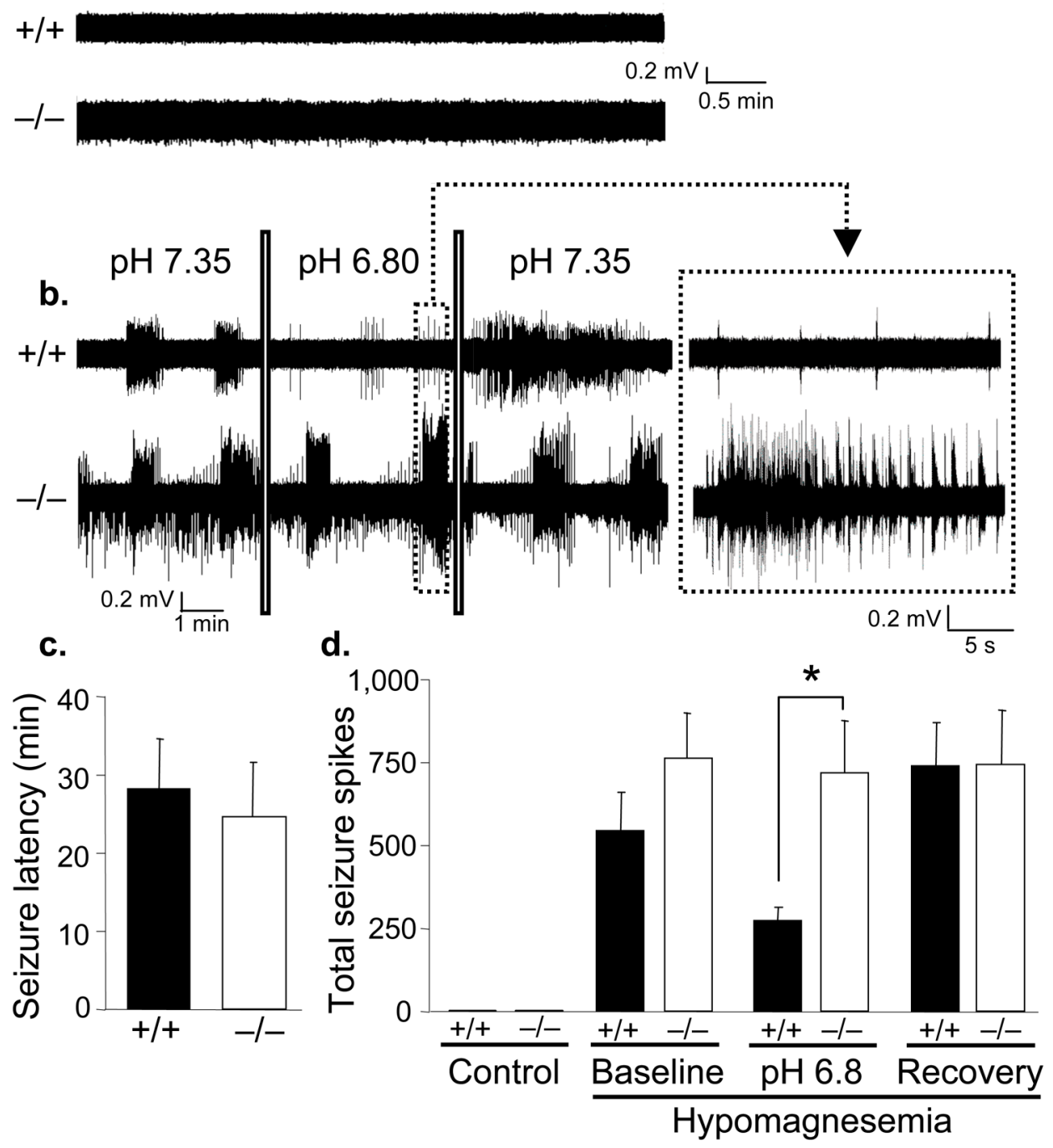

Figure 4.

ASIC1a mediates the antiepileptic effects of acid in hippocampal slices. (a) Representative CA3 extracellular recording from $\mathrm{ASICla}{ }^{+/+}$and $\mathrm{ASICla} \mathrm{a}^{-/-}$slices prior to ictal activity caused by hypomagnesemia (nominal $\mathrm{Mg}^{2+}$ ). (b) Representative CA3 recordings from $A S I C 1 a^{+/+}$and $A S I C l a^{-1-}$ slices demonstrating ictal activity before, during, and after $\mathrm{pH} 6.8$ application. A seizure-like discharge during pH 6.8 is expanded in the inset. (c) Latency to seizure onset was recorded in CA3 in response to $0 \mathrm{Mg}^{2+}(+/+, \mathrm{n}=7 ;-/-\mathrm{n}=5 ; \mathrm{t}(10)=0.366, \mathrm{p}=0.722)$. (d) Total number of seizure spikes over $4.5 \mathrm{~min}$. before induction of ictal activity (control), and then in the presence of nominal $\mathrm{Mg}^{2+}$ at $\mathrm{pH} 7.35$ (baseline), $\mathrm{pH}$ 6.8, and after return to $\mathrm{pH} 7.35$ (recovery) $(+/+, \mathrm{n}=9 ;-/-\mathrm{n}=8)$. In $\mathrm{ASICla} a^{+/+}$mice an ANOVA revealed a significant effect of $\mathrm{pH}(\mathrm{F}(2)=7.124, \mathrm{p}=0.006)$, however this was not the case in the $A$ SICla ${ }^{-1}$ mice $(\mathrm{F}(2)=$ $0.104, \mathrm{p}=0.902)$. A within-subjects comparison revealed a significant $\mathrm{pH} \mathrm{x}$ genotype interaction $(\mathrm{F}(2)=3.78, \mathrm{p}=0.034)$. At $\mathrm{pH} 6.8$, the spike number was significantly greater in the ASIC $1 a^{-1-}$ mice (unpaired t-test: $\mathrm{t}(15)=-2.88,{ }^{*} \mathrm{p}=0.006$ ), whereas at baseline and during recovery, the $A S I C l a^{+/+}$and $A S I C l a^{-/-}$mice did not significantly differ (unpaired $\mathrm{t}-$ test, $\mathrm{p}=$ 0.238 and 0.581 respectively). 
a. $\mathrm{ASIC}^{+1 /+}$

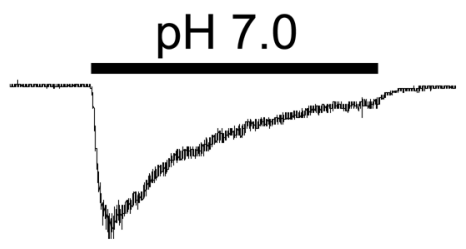

b.

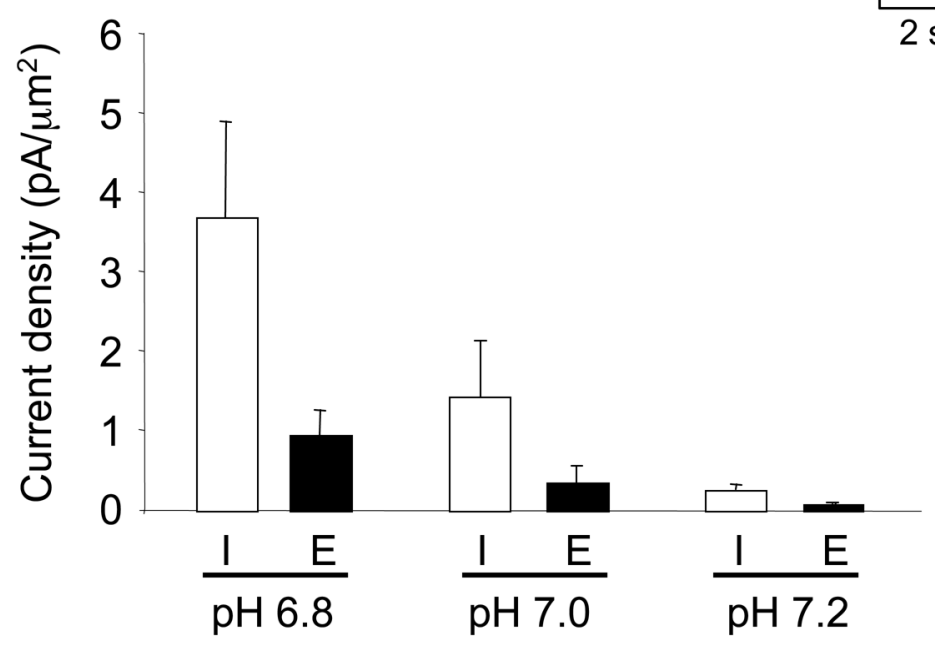

C.

$\mathrm{ASIC}^{\mathrm{a}} \mathrm{a}^{+/+}$

$\mathrm{pH} 7.0$

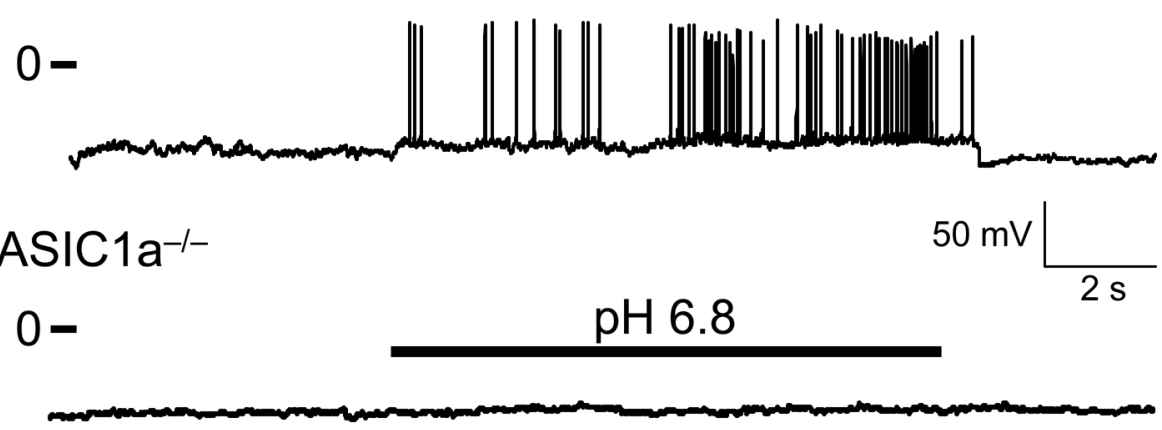

Figure 5.

Inhibitory interneurons have prominent ASIC1a currents. (a) Representative traces of acidevoked current in interneurons from the hippocampus of $\mathrm{ASICla}^{+/+}$and $\mathrm{ASICla}^{-/-}$mice.

Application of $\mathrm{pH} 7.0$ evoked an inward current in $+/+$, but not $-/-$ neurons. (b) From $\mathrm{ASICla}^{+/+}$mice, inhibitory neurons (I) had larger acid-evoked current density than excitatory pyramidal neurons (E) at $\mathrm{pH} 6.8-7.2$ (inhibitory, $\mathrm{n}=30$; excitatory, $\mathrm{n}=18 ; \mathrm{F}(1,42)=10.5$, $\mathrm{p}$ $<0.01$ ). (c) Current-clamp recording demonstrating acid-evoked firing in an $\mathrm{ASICla}^{+/+}$ inhibitory neuron. $\mathrm{ASICla}^{-/-}$neurons did not respond to even greater reductions in $\mathrm{pH}$. $\mathrm{pH} 6.8$ stimulated firing in 78\% $(\mathrm{n}=9)$ and $\mathrm{pH} 7$ stimulated firing in $80 \%(\mathrm{n}=5)$ of $\mathrm{ASICla}^{+/+}$ inhibitory neurons. 
a.
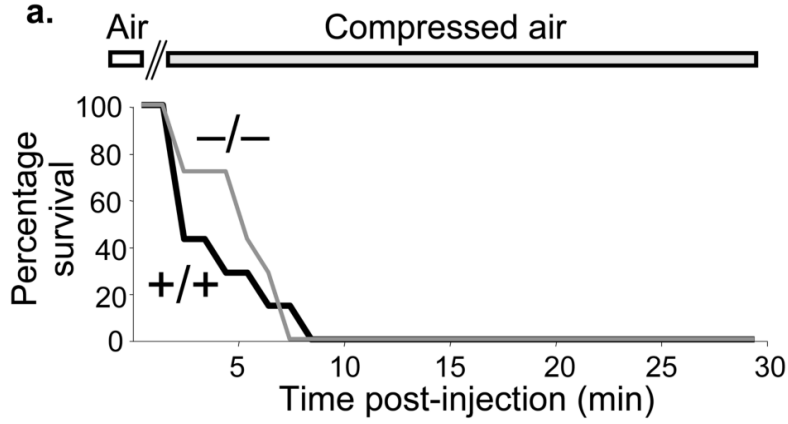

b.
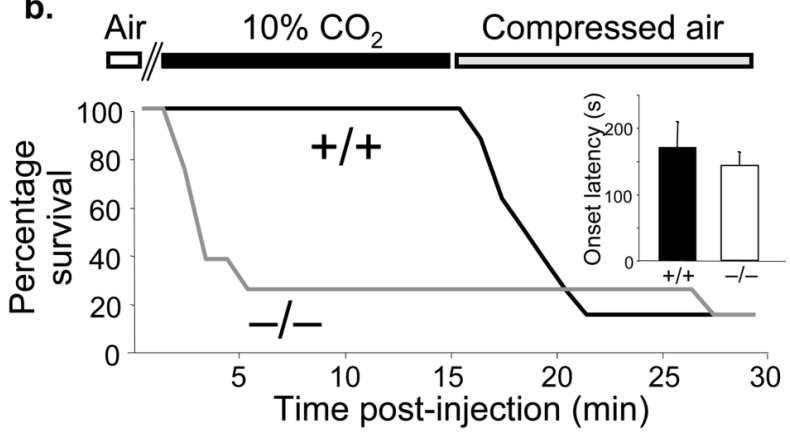

c.

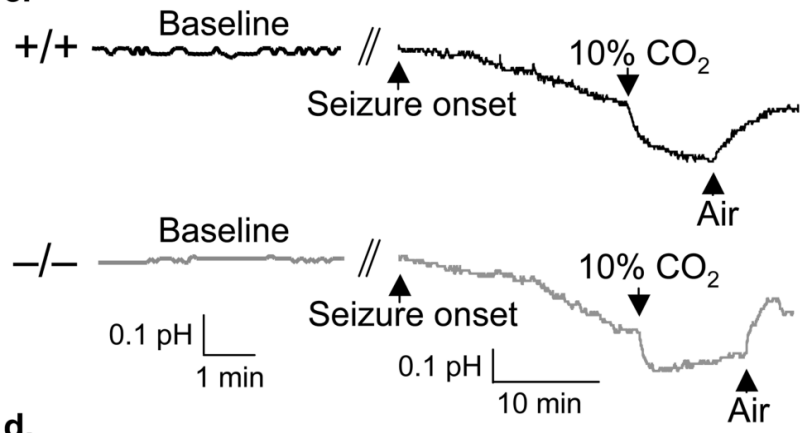

d.

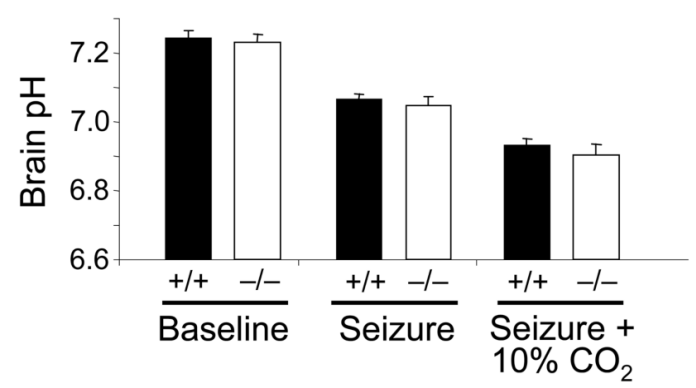

Figure 6.

ASIC1a mediates the seizure-terminating effects of $10 \% \mathrm{CO}_{2}$. (a) Kaplan-Meier survival analysis of $A S I C l a^{+/+}$and $A S I C l a^{-/-}$mice in response to PTZ injection ( $90 \mathrm{mg} / \mathrm{kg}$ IP) while breathing compressed air $(+/+, \mathrm{n}=7 ;-/-, \mathrm{n}=7$, age 13-16 weeks). Both $+/+$ and $-/-$ mice had the same survival rate (Mantel-Cox Log Rank, $\mathrm{p}=0.582$ ). (b) In a parallel experiment, $10 \% \mathrm{CO}_{2}$ was administered at the onset of generalized tonic-clonic seizures. The onset latency and time of $\mathrm{CO}_{2}$ administration was similar between genotypes (inset) (unpaired $\mathrm{t}-\mathrm{test}, \mathrm{t}(14)$ $=0.663, \mathrm{p}=0.518$ ). The chamber was perfused with $\mathrm{CO}_{2}$ until minute 15 , and then switched to compressed air for the duration of the trial $(+/+, \mathrm{n}=8 ;-/-, \mathrm{n}=8$, age 13-16 weeks). In $\mathrm{CO}_{2}$, the likelihood of survival was significantly greater in the $A S I C 1 a^{+/+}$mice (Mantel-Cox 
Log Rank, $\mathrm{p}=0.002)$. (c) Representative $\mathrm{pH}$ tracings from a $+/+$ and $-/-$ mouse brain before PTZ injection, during seizure, and during seizure and $10 \% \mathrm{CO}_{2}$ inhalation. (d) ASIC1a expression did not significantly alter brain $\mathrm{pH}$ prior to injection $(\mathrm{p}=0.784)$, during seizures ( $\mathrm{p}=0.627$ ), or during $\mathrm{CO}_{2}$ inhalation $(\mathrm{p}=0.528)$ (pre-injection: $+/+, \mathrm{n}=5 ;-/-, \mathrm{n}=5$, age 13-15 weeks; $\mathrm{t}(4)=0.283$; seizure: $+/+, \mathrm{n}=5 ;-/-, \mathrm{n}=5 ; \mathrm{t}(4)=0.505 ; \mathrm{CO}_{2}:+/+, \mathrm{n}=4 ;-/-$, $\mathrm{n}=4 ; \mathrm{t}(3)=0.670)$. 